\title{
ARTICULANDO A ETNOGRAFIA E A GROUNDED THEORY NA PESQUISA DO CONSUMIDOR
}

Marcelo de Rezende Pinto

marcrez@hotmail.com

Pontifícia Universidade Católica de Minas Gerais - Belo Horizonte, MG / Brasil

http://dx.doi.org/10.1590/1413-2311023201342135

Recebido em 24/06/2013

Aprovado em 06/05/2014

Disponibilizado em 01/08/2014

Avaliado pelo sistema double blind review

Revista Eletrônica de Administração

Editor: Luís Felipe Nascimento

ISSN 1413-2311 (versão on-line)

Editada pela Escola de Administração da Universidade Federal do Rio Grande do Sul.

Periodicidade: Quadrimestral

Sistema requerido: Adobe Acrobat Reader.

\section{RESUMO}

Este trabalho tem por objetivo relatar a experiência de campo de um pesquisador que buscou articular em um mesmo desenho de pesquisa a utilização da grounded theory (em sua vertente construtivista) e a etnografia. Para isso, buscou-se dividir o trabalho em três partes distintas. Na primeira parte, foram apresentadas de forma sucinta as duas metodologias de uma maneira ampla, introduzindo alguns dos seus princípios fundamentais. $\mathrm{Na}$ segunda parte, foram descritos os principais pontos do trabalho de campo que foi realizado com o objetivo de investigar a forma como os consumidores brasileiros oriundos das classes mais populares vivenciam suas experiências de consumo de produtos eletrônicos. Essa parte do artigo destaca algumas reflexões acerca das exigências práticas para a "operacionalização" de pesquisas comprometidas com "espírito" da etnografia e da grounded theory, explora os pontos de aderência, bem como joga luz sobre algumas questões desafiadoras que ainda exigem uma reflexão maior acerca da conjugação entre as duas metodologias. Por fim, de forma breve, tentou-se esboçar, à guisa de uma conclusão, as possíveis contribuições para a pesquisa do consumidor da articulação entre as metodologias.

Palavras-chave: Etnografia; Grounded Theory; Pesquisa do consumidor.

\section{LINKING ETHNOGRAPHY AND GROUNDED THEORY IN CONSUMER RESEARCH}

\begin{abstract}
This paper aims to report the experience of a field researcher who sought to organize in the same research design using grounded theory constructivist and ethnography. For this, we sought to divide the work into three distinct parts. In the first part, we presented succinctly the two methodologies in an extensive way, introducing some of its fundamental principles. In the second part, we describe the main points of the field work that was conducted in order to
\end{abstract}

$$
\text { REAd | Porto Alegre - Edição } 78 \text { - N } 2 \text { - maio/agosto } 2014 \text { - p. 397-424 }
$$


Articulando a Etnografia e a Grounded Theory na pesquisa do consumidor

investigate how Brazilian consumers derived of poor class experience their consumer experiences of electronic products. This part of the article highlights some reflections on the practical requirements for the "operationalization" of research committed to the "spirit" of ethnography and grounded theory, explores the points of adhesion, and throws light on some challenging issues that still require more thought about the conjunction between the two methodologies. Finally, briefly, tried to sketch, by way of a conclusion, the possible contributions to consumer research linking methodologies.

Keywords: Ethnography; Grounded Theory; Consumer Research.

\title{
LA ARTICULACIÓN DE LA ETNOGRAFÍA Y LA TEORÍA FUNDAMENTADA EN LA INVESTIGACIÓN DE LOS CONSUMIDORES
}

\begin{abstract}
RESUMEN
Este artículo tiene como objetivo informar de la experiencia de un investigador de campo que trataron de organizar en el mismo diseño de la investigación utilizando la teoría fundamentada (en su capítulo constructivista) y la etnografía. Para ello, hemos tratado de dividir el trabajo en tres partes bien diferenciadas. En la primera parte, se presentaron brevemente las dos metodologías de manera extensiva con la introducción de algunos de sus principios fundamentales. En la segunda parte, se exponen los principales puntos del trabajo de campo que se realizó con el fin de investigar la forma en los próximos consumidores brasileños de las clases más populares a experimentar sus experiencias de productos de electrónica de consumo. En este artículo se destacan algunas de las reflexiones sobre las prácticas para la "puesta en marcha" de la investigación comprometida con el "espíritu" de la etnografía y la teoría fundamentada, requisitos explora los puntos de adhesión, y arroja luz sobre algunas cuestiones difíciles que aún requieren mayor consideración acerca de la combinación entre las dos metodologías. Por último, en pocas palabras, hemos tratado de esbozar, a modo de conclusión, las posibles contribuciones a la investigación de los consumidores de la relación entre las metodologías.
\end{abstract}

Palabras clave: Etnografía; Teoría Fundamentada; La investigación del consumidor.

\section{INTRODUÇÃO}

Pode-se perceber nos últimos anos uma maior preocupação por parte dos pesquisadores do campo da pesquisa do consumidor no sentido de se propor "leituras" alternativas para o entendimento dos fenômenos do consumo. Este contexto tem obrigado os pesquisadores a (re) estabelecerem conversações com outras disciplinas tais como a Filosofia, a Sociologia e a Antropologia, o que leva a um processo de "abertura" no campo, no qual "novas" abordagens metodológicas têm surgido. Entre elas, destacam-se a etnografia e a grounded theory como opções relevantes.

REAd | Porto Alegre - Edição 78 - N 2 - maio/agosto 2014 - p. 397-424 
Marcelo de Rezende Pinto

Foi a partir das questões levantadas por Pettigrew (2000) e Goulding (2005), ao proporem a utilização de métodos originados de outras disciplinas, como sociologia e antropologia, em pesquisas de comportamento do consumidor, e defender a combinação da abordagem da etnografia com a metodologia denominada grounded theory, que surgiu o interesse em pesquisar mais sobre como se poderia conciliar essas duas metodologias em uma pesquisa de campo. Conforme também percebido por Ayrosa e Sauerbronn (2006), Lourenço et al. (2007) e Tarozzi (2011) e defendido por Charmaz e Mitchell (2001), a similaridade entre essas metodologias indica que a etnografia oferece uma forma de coleta de dados que é compatível com o método de construção de teorias proposto pela grounded theory.

Passados alguns anos, a preocupação mudou um pouco. O desafio agora não é mais apresentar uma proposta e encontrar similaridades e complementaridades entre elas, mas sim descrever uma situação na qual fosse possível expor para outros pesquisadores o processo de conciliar tais metodologias em um trabalho de campo real. Assim, quando se iniciou a discussão acerca da possibilidade de empreender um esforço de elaborar um trabalho no qual seria interessante trazer para os fóruns especializados em marketing, e mais precisamente na pesquisa do consumidor, a exposição da articulação de metodologias consideradas "pouco usuais" como a etnografia e a grounded theory, havia a certeza de que não era importante falar sobre os seus fundamentos, procedimentos formais e/ou características marcantes. Isso já foi (e tem sido) empreendido há algum tempo. Felizmente, já se conta com trabalhos nacionais relevantes nesse sentido para a etnografia (ROCHA et al, 1999; BARROS, 2002; ROCHA e BARROS, 2004; MARÇAL e BRANDÃO, 2008; FLORES-PEREIRA e CAVEDON, 2009; ALCADIPANI, 2010) e para a grounded theory (ISCHIKAWA e SANTOS, 2001; BANDEIRA-DE-MELO e CUNHA, 2006; BANDEIRA-DE-MELLO e GARREAU, 2009; CARISIO et al, 2008; PETRINI e POZZEBON, 2008; PINTO e SANTOS, 2012) que podem servir de referência. O foco e interesse é mostrar a tentativa de articulação ou combinação das duas metodologias em um mesmo "desenho" de pesquisa, relatando a experiência de um pesquisador que se propôs a tal tarefa.

De maneira geral, o objetivo é de contribuir para trazer para o campo da pesquisa do consumidor a possibilidade de articulação da etnografia com a grounded theory enquanto um estilo de pesquisa incentivando outros pesquisadores aqui do/no Brasil a se lançarem nessa empreitada. Almeja-se apresentar, com detalhes, como se desenrolou uma pesquisa com a proposta de articular as duas abordagens e, principalmente, ressaltar os possíveis pontos de aderência. Espera-se, com isso, não só fornecer algumas pistas para aqueles que pretendem REAd | Porto Alegre - Edição 78 - N² 2 - maio/agosto 2014 - p. 397-424 
Articulando a Etnografia e a Grounded Theory na pesquisa do consumidor desenvolver pesquisas nos moldes aqui apresentados, mas também instigar e convidar os demais colegas que já desenvolveram pesquisas segundo essas abordagens metodológicas, a também compartilhar suas idéias e vivências de modo que possamos refletir sobre nossas práticas, ao mesmo tempo em que possamos contar com novas possibilidades metodológicas complementares e/ou alternativas para compreender esse "ente" tão complexo, mutável e curioso com o consumidor.

Para tanto, dividiu-se o trabalho em quatro partes. Na primeira delas, ainda que esse não seja o foco principal, apresenta-se, de forma sucinta, a etnografia e a grounded theory de uma maneira ampla, a fim de familiarizar o leitor "não iniciado" com a temática da discussão e de dar-lhe algumas referências de onde possam partir construir um esforço de aprofundamento nas diferentes questões que circundam esse "estilo" de fazer pesquisa social. Na segunda parte, chega-se ao ponto principal do texto. É lá onde será descrito o trabalho de campo que foi realizado com o objetivo de investigar a forma como os consumidores brasileiros oriundos das classes mais populares vivenciam suas experiências de consumo de produtos eletrônicos em uma perspectiva simbólica. Tal como dito anteriormente, a preocupação do presente trabalho não é descrever os resultados da pesquisa, mas o processo de pesquisa ou, mais precisamente, a "costura" das duas metodologias em uma pesquisa empírica com ênfase especial nas contribuições e nos pontos de aderência entre ambas. Para isso, julgou-se adequado subdividir essa seção nos seguintes tópicos: entendendo a proposta, apresentando os aspectos gerais da pesquisa, definindo a área substantiva e o problema da pesquisa, trabalhando em campo, observando e entrevistando, selecionando os entrevistados, analisando os dados, construindo a teoria e retornando à literatura. A terceira parte apresenta algumas reflexões relacionadas aos desafios vivenciadas pelo pesquisador ao longo de todo o processo de pesquisa. Por fim, a última seção, busca apontar algumas contribuições metodológicas para a pesquisa do consumidor a partir da conjugação da etnografia e da grounded theory.

\section{ENTENDENDO A ETNOGRAFIA E A GROUNDED THEORY COMO ABORDAGENS METODOLÓGICAS}

\subsection{A etnografia}

Atualmente, com a sua difusão e crescente utilização em diversos campos das ciências sociais, já não se pode falar de apenas "uma", mas de várias etnografias. Se, um dia já foi 


\section{Marcelo de Rezende Pinto}

possível identificar características e/ou preceitos gerais que serviam para "dar forma" ao que se chamava etnografia, no presente, chegar a esse "consenso" não seria tarefa fácil (HAMMERSLEY, 1992; DENZIN e LINCOLN, 2006; ATKINSON et al., 2001; FINE, 2003). Porém, pode-se dizer, retomando as palavras do "pai" da etnografia - Bronislaw Malinowski - que a "essência" do método etnográfico está em "[...] apreender o ponto de vista dos nativos, seu relacionamento com a vida, sua visão do seu mundo [...] devemos, portanto, estudar tudo aquilo que mais intimamente lhe diz respeito, ou seja, o domínio que a vida exerce sobre ele.” (MALINOWSKI, 1978, p. 33-34).

Outra referência importante, principalmente relacionada às questões metodológicas da etnografia, é o trabalho de Clifford Geertz. Geertz (1978) apresenta o método etnográfico como uma descrição densa, em que o pesquisador procura construir uma descrição em profundidade das culturas como "teias de significado" que devem ser apreendidas. Esse tipo de descrição vai além de um relato detalhado daquilo que foi observado procurando chegar até os significados simbólicos e culturais que estão por trás das ações humanas. Tudo o que foi (é) observado, precisa ser entendidos dentro de um sistema que faça sentido e que explique as razões culturais dos comportamentos observados. O que distingue essa descrição densa de uma superficial é que esta descreve o ato de piscar como uma "rápida contração das pálpebras", enquanto aquela distingue as diferentes estruturas significantes envolvidos nesse ato que pode ser um mero tique nervoso, um sinal de cumplicidade, uma forma de comunicação, uma imitação (GEERTZ, 1978).

Do ponto de vista metodológico, a etnografia consiste no processo de observar, participar e conversar com o "nativo" em suas condições reais de existência, tentando entender e mapear a completude de sua vida, os diferentes princípios, as "lógicas" e os significados por meio dos quais as pessoas atribuem sentido e organizam a "realidade" em que vivem (BARBOSA, 2003). O trabalho de campo, que normalmente envolve uma combinação de observação direta e entrevistas em profundidade, permite que o "ponto de vista nativo" sobre as experiências e práticas cotidianas seja enriquecido por informação visual e emocional - ethos - que permeia a situação (BARBOSA, 2003). Esse encontro etnográfico é que propicia ao pesquisador uma oportunidade única e uma maneira diferente de olhar para a realidade de um grupo de pessoas.

Especificamente, no que diz respeito à pesquisa do comportamento do consumidor, Elliott e Jankel-Elliott (2003) apontam que o método etnográfico pode ser útil para a compreensão profunda da experiência viva dos consumidores entendidos como seres sociais.

REAd | Porto Alegre - Edição 78 - N 2 - maio/agosto 2014 - p. 397-424 
Articulando a Etnografia e a Grounded Theory na pesquisa do consumidor

Dentre os pressupostos básicos do método etnográfico, que contribuem para isso, os autores destacam: (a) o estudo do comportamento social no mundo real; (b) a crença de que não há como apreender esse comportamento sem entender o mundo simbólico dos sujeitos, alcançando seus pontos de vista e tendo contato com os significados compartilhados em grupo e expressos na linguagem da vida cotidiana; (c) a imersão em um trabalho de campo de longa duração, que aumenta a possibilidade de entrar em contato com momentos importantes e "imponderáveis" do dia a dia dos informantes, bem como com incidentes reveladores; (d) buscar a compreensão das regras locais que orientam a visão de mundo dos atores sociais.

\subsection{A Grounded Theory}

O livro "The Discovery of Grounded Theory", publicado por Barney G. Glaser e Anselm L. Strauss em 1967, é o grande marco do "nascimento" da grounded theory (traduzida em português para teoria fundamentada nos dados) enquanto estilo de se fazer pesquisa social. Nele, os autores procuraram articular, sistematizar e apresentar as estratégias de pesquisa que construíram em seus trabalhos conjuntos realizados na década de 60 sobre a experiência da morte (dying) em hospitais dos EUA. Naquela época, em que toda uma tradição de pesquisa qualitativa estava perdendo espaço nas universidades, nas publicações científicas e nas agências de fomento, para os métodos quantitativos cada vez mais sofisticados, a grounded theory representou uma reação e se estabeleceu como uma alternativa à hegemonia da lógica hipotético-dedutiva dos trabalhos de orientação positivista nos estudos sociológicos (CHARMAZ, 2006). Glaser e Strauss (1967) estavam preocupados em desenvolver uma metodologia, ou um estilo de se fazer pesquisa, que fosse capaz de preencher o espaço existente entre o que eles chamaram de "pesquisas empíricas teoricamente desinteressadas" e de "teorias empiricamente desinteressadas", que predominavam nas ciências sociais naquela época - o esforço havia sido todo concentrado apenas em "validar" teorias existentes, e muito pouco estava sendo feito no sentido de construir novas teorias (CHARMAZ, 2006).

Assim, o foco da atenção parecia estar em estabelecer (e tentar legitimar) um estilo de pesquisa em que fosse possível falar de pesquisas empíricas teoricamente interessadas, ou seja, direcionadas não para o teste de hipóteses já previamente estabelecidas segundo os pressupostos das grandes teorias (abstratas, generalizáveis, formais, mas distantes do "dia-adia das pessoas"), já disponíveis mas principalmente para a construção de "novas" hipóteses e de “novas teorias". Segundo Glaser e Strauss (1967), as teorias geradas segundo a lógica

REAd | Porto Alegre - Edição 78 - N² 2 - maio/agosto 2014 - p. 397-424 


\section{Marcelo de Rezende Pinto}

"positivista científica" da época, apesar de serem formuladas de maneira muito sistematizada, ou justamente por esse excesso de sistematização, se revelavam muito abstratas e tinham muito mais a ver com os (pré)conceitos teóricos prévios dos pesquisadores, do que propriamente com a "realidade empírica". Se o pesquisador estiver muito comprometido com uma teoria pré-definida em particular, ele pode se tornar doutrinário e pode não conseguir enxergar além dos limites do arcabouço teórico que escolheu (GLASER e STRAUSS, 1967, p.46).

Foi na tentativa de minimizar esse tipo de problema que Glaser e Strauss (1967) procuraram conceber um método de pesquisa em que o pesquisador, ao invés de "forçar" pressuposições ou categorias/conceitos teóricos pré-existente, ou seja, de tomar a teoria como ponto de partida, deveria procurar conceber uma teoria fundamentada em dados a partir, e representativos da "realidade" dos sujeitos estudados, ou seja, tomar a construção teórica como ponto de chegada. No modelo de pesquisa da grounded theory, esse movimento é invertido, aqui o pesquisador parte desde a observação empírica "lá fora" para só então começar a definição de conceitos (LOCKE, 2001). A idéia, nesse caso, é começar a pesquisa não pela definição de uma estrutura teórica-analítica, mas sim com um problema geral concebido apenas em termos de perspectivas disciplinares mais amplas (DEY, 1999). Essa área substantiva de pesquisa seria suficiente como ponto de partida para que o pesquisador decida o que e onde estudar. Uma vez tendo identificado o problema - definido em termos gerais - e selecionado o lugar onde esse problema pode ser estudado, o pesquisador deve permitir que as evidências que, aos poucos vão emergindo e se somando, ditem a sua agenda de pesquisa (DEY, 1999).

No entanto, quando se fala de uma teoria que emerge dos dados, parece natural perguntar sobre que tipo de teoria é essa. Glaser e Strauss (1967) utilizam uma classificação que considera dois tipos de teoria: formal e substantiva. As teorias formais são mais amplas, mais gerais e têm a pretensão de poderem ser generalizadas, ou seja, de se aplicarem a uma grande variedade de disciplinas, interesses e problemas (GOULDING, 2002). As teorias substantivas, por sua vez, procuram refletir a complexidade da vida social. São específicas, limitadas em seu escopo, ricas em detalhes e aplicáveis apenas dentro dos limites de um dado contexto social. Sem a preocupação de generalização estatística para além da sua área substantiva, procura aprofundar a explicação de uma "realidade" local, particular, construída a partir das experiências vividas por um determinado grupo social (DEY, 1999; GOULDING, 2002). É à geração de teorias substantivas, especialmente importantes quando se trata de um REAd | Porto Alegre - Edição 78 - N² 2 - maio/agosto 2014 - p. 397-424 
Articulando a Etnografia e a Grounded Theory na pesquisa do consumidor

fenômeno social insuficientemente explicado pelas teorias formais existentes, que a grounded theory se propõe. Esse tipo de teoria se "encaixa" e "funciona" bem porque é construída com conceitos e categorias que emergem a partir dos termos que os próprios agentes sociais usam para interpretar e organizar o seu mundo. Locke (2001) insiste nesse ponto afirmando que uma "boa" teoria substantiva deve ser útil no dia-a-dia não apenas para os sociólogos, mas também para os "leigos". Isto é, ela precisa ser apreensível, compreensível, relevante para a prática e aplicável em diferentes situações/condições à luz da "realidade cotidiana" das pessoas que vivem o processo social que está sendo investigado. Conseguir isso não é, entretanto, uma tarefa fácil.

\section{A ETNOGRAFIA E A GROUNDED THEORY ARTICULADAS EM UMA PESQUISA DO CONSUMIDOR}

\subsection{Entendendo a proposta}

É importante ressaltar que a proposta do trabalho é relatar a experiência de campo de um pesquisador em uma investigação sobre consumo, com foco especial nos pontos de aderência entre as duas abordagens, ou seja, não é apresentar os resultados da pesquisa, mas sim o processo de investigação e como aconteceu a articulação entre as duas abordagens nos vários momentos.

\subsection{Fazendo escolha - A Grounded Theory construtivista}

Retomando a breve explanação da grounded theory em uma das seções anteriores, julgou-se pertinente, nesse tópico do trabalho, retomar essa explanação a fim de tecer algumas considerações atinentes ao tipo (ou escola) de grounded theory adotada no trabalho. Para isso, é necessário retomar a trajetória dos seus dois criadores - Barney G. Glaser e Anselm L. Strauss após o sucesso do livro seminal "The Discovery of Grounded Theory" publicado em 1967. As relações entre os dois "pais" da metodologia ficaram estremecidas após a publicação de Strauss juntamente com Juliet Corbin do livro “Basics of Qualitative Research" em 1991, quando Glaser critica severamente o trabalho afirmando que destrói a concepção inicial da metodologia. Desde então, por meio de trabalhos independentes (com ou sem coautoria), eles têm mantido um debate no qual é possível perceber duas correntes: a glaseriana e a strausscorbiana.

REAd | Porto Alegre - Edição 78 - N² 2 - maio/agosto 2014 - p. 397-424 


\section{Marcelo de Rezende Pinto}

Partindo da proposta da pesquisa que é articular a grounded theory com a etnografia, optou-se nesse trabalho por uma vertente que se aproxima mais da vertente strauss-corbiniana. Em primeiro lugar, por ser uma abordagem mais estruturada, "acessível” e preocupada com a operacionalização da pesquisa, conta com um arsenal de procedimentos e práticas que são importantes para possibilitar a execução de um bom trabalho em curtos espaços de tempo. Em segundo lugar, porque se afina à proposta da pesquisa, que é entender o caráter simbólico da experiência de consumo de um grupo de consumidores.

Também é importante salientar que a proposta da vertente strauss-corbianiana é coincidente com o que Charmaz (2006) chama de grounded theory construtivista. Na visão da autora, uma abordagem construtivista coloca prioridade no fenômeno de estudo e busca tanto dados quanto análises construídas a partir das experiências e relacionamentos compartilhados com os participantes do estudo. No mesmo sentido, um estudo construtivista procura entender como e por que os participantes constroem significados e ações em situações específicas. A teoria depende da visão do pesquisador; isto é, ele não está e não pode estar fora do contexto que está sendo investigado. Além disso, a extensão lógica da abordagem do construtivismo significa aprender como, quando e em que extensão a experiência estudada está mergulhada na ampla e, muitas vezes, escondida posições, redes, situações e relacionamentos.

\subsection{Apresentando os aspectos gerais da pesquisa}

A pesquisa desenvolvida situa-se no campo da pesquisa do consumidor. O objetivo principal da pesquisa era investigar como as experiências de consumo de eletrônicos pelos consumidores de baixa renda interagem com o sistema cultural e simbólico envolvido no fluxo da vida social cotidiana.

\subsection{Definindo a área substantiva e a problema de pesquisa}

Como ponto de partida, vale destacar que em estudos baseados na grounded theory, o pesquisador não começa o seu projeto com uma teoria preconcebida. Ao contrário, opta por iniciar com uma área de estudo ampla, permitindo que a teoria vá emergindo dos dados ao longo do processo de pesquisa. Assim, não se assume um referencial teórico a priori, visto que não se conhece o que é relevante para os sujeitos envolvidos (BANDEIRA-DE-MELLO e CUNHA, 2006). Uma vez tendo identificado o problema - definido em termos gerais - e selecionado o lugar onde esse problema pode ser estudado, o pesquisador deve permitir que as 
Articulando a Etnografia e a Grounded Theory na pesquisa do consumidor

evidências que, aos poucos vão emergindo e se somando, ditem a sua agenda de pesquisa (DEY, 1999).

Por isso, a revisão da literatura conduzida no estudo limitou-se a apresentar um breve estado da arte da área de conhecimento com alguns elementos relevantes, com vistas a perceber "lacunas" que poderiam ser supridas pela construção da teoria substantiva. Vale destacar também que as questões de pesquisa foram abertas e gerais, e, evidentemente, não formalizadas na forma de hipóteses específicas.

O Quadro 1 tenta sintetizar a proposta da etnografia e da grounded theory e aponta alguns pontos de aderência entre as abordagens nessa fase da pesquisa.

Quadro 1 - Pontos de aderência entre a etnografia e a grounded theory na fase de definição do problema de pesquisa

\begin{tabular}{|l|l|l|}
\hline \multicolumn{1}{|c|}{ ETNOGRAFIA } & \multicolumn{1}{|c|}{ PONTOS DE ADERENCIA } & \multicolumn{1}{c|}{ GROUNDED THEORY } \\
\hline A proposta da etnografia é & A etnografia parece ser & A proposta da grounded \\
observar, participar e & adequada para "alimentar" a & theory caminha no sentido de \\
entrevistar o "nativo" em & construção da teoria, visto & ser útil nos casos nos quais o \\
suas condições reais de & que o pesquisador vai ter & objetivo da pesquisa é \\
existência, tentando entender & contato com a realidade dos & entender como as pessoas se \\
e mapear a completude de & sujeitos sem modelos pré- & comportam num contexto \\
sua vida, os diferentes & concebidos, visando o o & social e essencialmente, ela é \\
princípios, as "lógicas" e os & preenchimento de uma & mais comumente utilizada \\
significados por meio dos & lacuna no conhecimento. & para gerar teoria onde pouco \\
quais as pessoas atribuem & & é sabido ou existem lacunas \\
sentido e organizam a & & no conhecimento \\
"realidade" em que vivem. & & (GOULDING, 2002). \\
\hline
\end{tabular}

Fonte: Elaborado pelo autor

A partir desses pontos de aderência, o processo da pesquisa caminhou para um estudo etnográfico no primeiro momento a fim de coletar, por meio de observação participante, elaboração de diários de campo e entrevistas, dados que pudessem servir de base para a construção da teoria.

\subsection{Trabalhando em campo}

Dadas as características da pesquisa, cumpre ressaltar a importância do trabalho de campo, pois ele é o elemento mais característico da pesquisa etnográfica. O trabalho de campo pressupõe uma interiorização por parte do pesquisador das significações que os indivíduos atribuem aos seus comportamentos, implicando uma integração do observador no trabalho de campo. Dois aspectos são importantes para o emprego da etnografia. O primeiro 


\section{Marcelo de Rezende Pinto}

refere-se ao recurso da tomada de notas e da elaboração sistemática do diário de campo. O segundo aspecto refere-se à complementaridade de outros procedimentos para a coleta de dados durante o trabalho de campo: análise de documentos, entrevistas semiestruturadas e a história de vida (ANDION e SERVA, 2006).

Essa fase da pesquisa pode ser dividida em três fases. A primeira foi marcada por conversas informais com os informantes, a fim de identificar alguns traços básicos do cotidiano deles, e a compreender a dinâmica das relações entre eles. A segunda fase do trabalho de campo foi marcada por visita às casas dos moradores e, principalmente, pela realização de entrevistas semiestruturadas. Nas visitas às casas dos moradores, busquei sempre perceber detalhes no tocante ao acabamento, organização e decoração dos móveis, lugar de instalação dos aparelhos ou qualquer outro aspecto que pudesse contribuir para o entendimento do dia a dia desses indivíduos. Finalmente, a terceira fase do trabalho de campo teve por objetivo fazer checagens com algumas das entrevistadas acerca de algumas categorias que emergiram da análise executadas e tentar aumentar a densidade da teoria em construção.

Fetterman (1998) salienta algumas questões ou "princípios", que não devem ser negligenciados por pesquisadores que se engajam em uma pesquisa de cunho etnográfico: permissão, honestidade, confiança, anonimato, reciprocidade e trabalho rigoroso. Com relação ao "princípio" da permissão, o pesquisador etnógrafo deve obter consentimento, formal ou não, por parte das pessoas envolvidas para conduzir seu trabalho. No caso do trabalho, a todos os entrevistados foi explicado o objetivo do trabalho e seu papel na condução das entrevistas e na observação. Em algumas situações, por exemplo, algumas entrevistadas se negaram a conceder entrevistas, mas aceitaram conversar informalmente, o que foi de grande valia. Outro "princípio" é o da honestidade, que enfatiza a importância de o pesquisador estar sempre disposto a dar explicações sobre o trabalho conduzido em campo. Nesse sentido, todas as vezes que algum morador mais curioso inquiria-me sobre o trabalho, tinha o maior cuidado em explicar todos os detalhes até que ele se sentisse satisfeito. Já o "princípio" da confiança é essencial para um trabalho etnográfico, visto que todos os entrevistados e envolvidos na investigação devem confiar no pesquisador, a fim de que ele possa "penetrar" nos vários níveis de significado pertencentes a cada ação e fato observado. Para responder adequadamente a esse princípio, optei por buscar construir uma relação de confiança com cada entrevistada antes de conduzir qualquer observação em sua casa ou de conduzir a entrevista. O "princípio" do anonimato leva em consideração que o pesquisador deve, na REAd | Porto Alegre - Edição 78 - N 2 - maio/agosto 2014 - p. 397-424 
Articulando a Etnografia e a Grounded Theory na pesquisa do consumidor

medida do possível, evitar revelar nomes ou situações que possam causar algum tipo de transtorno ou risco para as pessoas envolvidas. Assim, decidi omitir nomes das entrevistadas, criando para cada uma delas um nome fictício. Por sua vez, o "princípio" da reciprocidade estabelece que o pesquisador pode participar ou contribuir de alguma forma com atividades pertencentes ao grupo pesquisado. No caso deste trabalho, posso afirmar que por diversas vezes fui convocado para auxiliar em alguma ação beneficente no bairro, convidado a contribuir com auxílio financeiro para a construção de alguma casa, invitado a doar roupas ou móveis para as muitas famílias carentes, sem contar as ocasiões que a mim foi solicitada a condução de algum doente para um hospital. Por fim, para atender ao "princípio" do trabalho rigoroso, é possível apontar, conforme dito anteriormente, que o trabalho de campo estendeuse por quinze meses, período no qual foi possível conviver com o público da pesquisa, conduzir observações e gravar entrevistas. Todas essas questões vêm a contribuir para dar mais credibilidade aos dados coletados em campo e, consequentemente, aumentar a qualidade da teoria construída.

Nesse sentido, o Quadro 2 tenta sintetizar a proposta da etnografia e da grounded theory e aponta alguns pontos de aderência encontrado entre as abordagens na fase de trabalho de campo.

Quadro 2 - Pontos de aderência entre a etnografia e a grounded theory na fase de trabalho de campo

\begin{tabular}{|l|l|l|}
\hline \multicolumn{1}{|c|}{ ETNOGRAFIA } & \multicolumn{1}{|c|}{ PONTOS DE ADERÊNCIA } & \multicolumn{1}{c|}{ GROUNDED THEORY } \\
\hline Em campo, a etnografia & A observação participante, os & Para Glaser (1978), o \\
oferece uma série de técnicas & diários de campo e as & pesquisador deve utilizar \\
de pesquisa para captar a & entrevistas em profundidade & todos os tipos de dados que \\
realidade dos sujeitos em & podem ser de grande valia & julgar relevante para a \\
campo tais como observação & para a construção da teoria & construção da teoria, \\
participante, elaboração de & fundamentada na realidade & envolvendo documentos, \\
diários de campo e & dos sujeitos pesquisados. & transcrição de entrevistas, \\
entrevistas em profundidade. & O suporte às “idas e vindas" & diários de campo, literatura \\
& a campo, ponto fundamental & técnica e não-técnica, entre \\
& da grounded theory, \\
& eutras. \\
& técnicas etnográficas. & \\
\hline
\end{tabular}

Fonte: Elaborado pelo autor

Conforme dito anteriormente, em um estudo baseado na grounded theory, é possível modificar muito facilmente as próprias categorias e as relações entre estas, assim como acrescentar novas categorias conforme vão aparecendo novos dados anteriormente desconhecidos. Isso foi obtido por meio de sucessivas "idas e vindas" a campo. Esta parece REAd | Porto Alegre - Edição 78 - N 2 - maio/agosto 2014 - p. 397-424 


\section{Marcelo de Rezende Pinto}

ser um dos principais pontos de aderência entre as duas metodologias, uma vez que a etnografia oferece um arsenal de técnicas plenamente adaptável para focalizar o olhar do pesquisador em questões relevantes do fenômeno em observação visando ao delineamento das categorias que comporão a teoria.

\subsection{Observando e entrevistando}

Para as entrevistas em profundidade, levei em consideração a orientação de Strauss e Corbin (2008) quando indicam que perguntas de entrevista inicial ou áreas de observação devem ser baseadas em conceitos derivados da literatura ou da experiência. Ou, melhor ainda, do trabalho de campo preliminar. À medida que o trabalho de campo avançava, juntamente com a análise dos dados, o roteiro de entrevista, gradativamente, sofria alterações e novas inclusões, advindas das categorias que emergiam.

Quanto ao roteiro de observação, busquei seguir as orientações de Mariampolski (2006), que entende que a ferramenta básica para conduzir uma pesquisa observacional é o guia de observação, compreendido como o estabelecimento de atenções sobre como as visitas procederão em termos de comportamentos a serem observados, tópicos a serem cobertos, a quantidade de tempo a ser gasto em cada área e a sequência de questões ou provas que serão introduzidas. Nesse sentido, optei por construir um guia de observação para ajudar nas visitas que conduzi nas casas dos moradores.

O Quadro 3 aponta questões referentes à etnografia e à grounded theory e os pontos de aderência entre ambas no tocante à observação e entrevista dos entrevistados.

Quadro 3 - Pontos de aderência entre a etnografia e a grounded theory na fase de observação participante e entrevista dos informantes

\begin{tabular}{|l|l|l|}
\hline \multicolumn{1}{|c|}{ ETNOGRAFIA } & \multicolumn{1}{|c|}{ PONTOS DE ADERÊNCIA } & \multicolumn{1}{c|}{ GROUNDED THEORY } \\
\hline Os autores adeptos da & Pôde-se verificar que as & Para os proponentes da \\
etnografia oferecem uma & ferramentas utilizadas em & grounded theory, quanto \\
série de ferramentas úteis & uma pesquisa de cunho & maior a quantidade de dados, \\
para o pesquisador referentes & etnográfico serviram de base & maior serão as possibilidades \\
ao trabalho de observar e & para a construção de uma & de construção de uma teoria \\
entrevistar os atores de uma & teoria substantiva. & que possa, de fato, explicar \\
pesquisa. & & uma determinada realidade. \\
\hline
\end{tabular}

Fonte: Elaborado pelo autor

Uma questão polêmica que quase invariavelmente gera dúvidas em um estudo envolvendo a grounded theory está relacionada com a forma de seleção dos entrevistados. Ao REAd | Porto Alegre - Edição 78 - N² 2 - maio/agosto 2014 - p. 397-424 
Articulando a Etnografia e a Grounded Theory na pesquisa do consumidor

articular a etnografia com a grounded theory a polêmica permanece em aberto. A próxima seção visa a apresentar algumas considerações acerca da questão a partir dos diversos autores de ambas as metodologias.

\subsection{Selecionando os entrevistados}

Levando-se em consideração as características do trabalho e a proposta dos autores proponentes da grounded theory (GLASER, 1992; STRAUSS e CORBIN, 2008; CHARMAZ, 2006; GOULDING, 2002), a estratégia de seleção dos entrevistados mais adequada foi a denominada "amostragem teórica", pois quando construímos teoria indutivamente a amostragem é direcionada pela própria teoria (GOULDING, 2002). Uma das definições do que vem a ser amostragem teórica é proposta por Strauss e Corbin (2008, p. 196):

Coleta de dados conduzida por conceitos derivados da teoria evolutiva e baseada no conceito de "fazer comparações", cujo objetivo é procurar locais, pessoas ou fatos que maximizem oportunidades de descobrir variações entre conceitos e de tornar densas as categorias em termos de suas propriedades e de suas dimensões.

Quanto a essa questão, o Quadro 4 apresenta os pontos importantes e os pontos de aderência entre as duas abordagens.

Quadro 4 - Pontos de aderência entre a etnografia e a grounded theory ao selecionar os entrevistados para compor o corpus da pesquisa

\begin{tabular}{|c|c|c|}
\hline ETNOGRAFIA & PONTOS DE ADERÊNCIA & GROUNDED THEORY \\
\hline $\begin{array}{l}\text { A seleção dos entrevistados } \\
\text { em um estudo de cunho } \\
\text { etnográfico deve ser } \\
\text { conduzida pelo pesquisador. } \\
\text { Não há uma preocupação em } \\
\text { se definir número de } \\
\text { entrevistados, nem critérios } \\
\text { fechados de seleção dos } \\
\text { pesquisados. }\end{array}$ & $\begin{array}{l}\text { Ambas as abordagens } \\
\text { parecem seguir as mesmas } \\
\text { orientações. Portanto, quanto } \\
\text { à questão de seleção dos } \\
\text { entrevistados as duas } \\
\text { abordagens } \\
\text { plenamente aderentes. }\end{array}$ & $\begin{array}{l}\text { Para Glaser (1992), o } \\
\text { processo de coleta de dados } \\
\text { em um estudo baseado na } \\
\text { grounded theory deve ser } \\
\text { controlado pela teoria } \\
\text { emergente. Assim, o } \\
\text { pesquisador não tem como } \\
\text { deve decidir de antemão o } \\
\text { tamanho do corpus, muito } \\
\text { menos quem serão os } \\
\text { indivíduos que farão parte da } \\
\text { pesquisa. O critério para a } \\
\text { seleção deve ter o propósito } \\
\text { de desenvolvimento teórico. }\end{array}$ \\
\hline
\end{tabular}

Fonte: Elaborado pelo autor

A próxima seção do trabalho discutirá os detalhes envolvendo a etapa de análise dos dados. 


\section{Marcelo de Rezende Pinto}

\subsection{Analisando os dados}

Ainda que nessa fase possa residir a questão que parece diferenciar ambas as abordagens de pesquisa, é possível encontrar alguns pontos de aderência, tal como apresentado no Quadro 5. Cabe ressaltar que, enquanto boa parte dos estudos etnográficos tem a preocupação de "descrever densamente" uma determinada realidade, a grounded theory tem a proposta de, a partir dessa descrição, dar um passo além, no sentido de chegar à construção de categorias e conceitos e a posterior integração entre eles com a identificação das relações. Ou seja, a grounded theory se situa justamente no ponto em que a etnografia mostra-se mais frágil que é a análise dos dados.

Sendo assim, não é escusado ressaltar que é a análise de dados que se constitui uma das principais fases do método da grounded theory, visto que a teoria emerge dos dados. Conforme já explanado anteriormente, é a análise que conduz a coleta de dados. Por isso, é salutar a interação constante entre o pesquisador e o ato de pesquisa, tornando essa interação um processo livre e "criativo", por meio do qual o pesquisador busca respostas analíticas para os fenômenos em análise.

Uma importante fase da análise dos dados foi a codificação dos dados, que é também de extrema importância para o método da grounded theory (MELLO, 2002; GOULDING, 2002; CHARMAZ, 2006). Assim, optei por seguir os procedimentos tal como proposto pelos autores. Para eles, o processo pode ser dividido em três etapas: codificação aberta, codificação axial e codificação seletiva. A codificação aberta envolveu a quebra, análise, comparação, conceituação e categorização dos dados. Após a identificação de categorias conceituais pela codificação aberta, a codificação axial examinou as relações entre categorias e subcategorias. Por fim, a codificação seletiva refinou todo o processo, identificando a categoria central da teoria, com a qual todas as outras estão relacionadas.

Ainda que existam alguns pontos polêmicos relacionados à escolha da melhor técnica para análise dos dados (GLASER, 1992, STRAUSS e CORBIN, 2008), no presente trabalho, lançou-se mão utilização da análise de conteúdo. É importante levar em consideração que a análise de conteúdo admite tanto análises qualitativas quanto quantitativas ou, ainda, ambas (BARDIN, 2011; LAVILLE e DIONNE, 1999). Contudo, neste trabalho pensei ser mais conveniente a utilização das análises qualitativas de conteúdo, visto que as abordagens mais qualitativas tendem a conservar a forma literal dos dados. Assim, o pesquisador pode prenderse mais às nuanças de sentido que existem entre as unidades e aos elos lógicos entre essas unidades ou entre as categorias que as reúnem (LAVILLE e DIONNE, 1999).

REAd | Porto Alegre - Edição 78 - N 2 - maio/agosto 2014 - p. 397-424 
Articulando a Etnografia e a Grounded Theory na pesquisa do consumidor

Vale comentar que, conforme já explicitado anteriormente, na grounded theory há uma sobreposição entre as fases de coleta e análise de dados. Assim, toda a fase de análise de dados começou a partir da elaboração das primeiras notas de campo e somente terminou com a redação do trabalho final.

Outro ponto fundamental da grounded theory proposto pelos diversos autores (STRAUSS e CORBIN, 2008, CHARMAZ, 2006) é a construção dos memorandos. Tal como enfatizado por Tarozzi (2011), eles são um instrumento metacognitivo no qual o pesquisador tem a possibilidade de refletir, polemizar, confrontar, discutir questões que favorecem, apoiam e guiam a emersão da teoria em todas as suas fases, da coleta de dados até a codificação teórica. Sua elaboração constitui um passo intermediário entre a coleta de dados e a escrita do relatório final de pesquisa. A conjugação do processo de elaboração dos memorandos com o trabalho etnográfico mostrou-se adequado pois percebeu-se uma bem vinda complementariedade entre as diversas notas constituintes dos diários de campo empreendidas nas observações de campo.

Nesse sentido, duas tarefas foram essenciais para a análise dos dados coletados na fase de trabalho de campo: a elaboração de questionamentos sobre os possíveis significados; e a condução de comparações, seguindo as orientações propostas por Strauss e Corbin (2008). Para esses autores, há dois tipos de comparação: teóricas e incidente-incidente. As comparações teóricas foram feitas no início das análises ou sempre que algo novo surgia dos dados. Já as comparações incidente-incidente foram feitas somente quando já existiam possíveis categorias definidas em suas propriedades e dimensões. Pode-se afirmar também que o método das comparações constantes, que pode ser definido por Strauss e Corbin (2008) como uma forma de identificar variações nos padrões encontrados nos dados, também mostrou-se facilitado pelo trabalho etnográfico, uma vez que a descrição proporcionada pelos diários de campo facilitou o "adensamento" teórico.

A fim de apontar os principais pontos de aderência entre a etnografia e a grounded theory na fase de análise dos dados, elaborou-se o Quadro 5. 
Marcelo de Rezende Pinto

Quadro 5 - Pontos de aderência entre a etnografia e a grounded theory na fase de análise de dados

\begin{tabular}{|c|c|c|}
\hline ETNOGRAFIA & PONTOS DE ADERÊNCIA & GROUNDED THEORY \\
\hline $\begin{array}{l}\text { A riqueza dos dados } \\
\text { proporcionada pelas } \\
\text { descrições construídas nos } \\
\text { diários de campo, além das } \\
\text { entrevistas em profundidade. }\end{array}$ & $\begin{array}{l}\text { As idas e vindas ao campo, } \\
\text { além da possibilidade de } \\
\text { utilizar as descrições } \\
\text { oriundas dos diversos diários } \\
\text { de campo mostraram-se } \\
\text { adequadas e aderentes às } \\
\text { técnicas de análise de dados } \\
\text { propostas pelos autores da } \\
\text { grounded theory. }\end{array}$ & $\begin{array}{l}\text { A fase de análise de dados } \\
\text { em um estudo envolvendo a } \\
\text { grounded theory pode ser } \\
\text { dividida em: codificação, } \\
\text { elaboração de } \\
\text { questionamentos, execução } \\
\text { de comparações e construção } \\
\text { de memorandos. }\end{array}$ \\
\hline
\end{tabular}

Fonte: Elaborado pelo autor

Tendo finalizado as discussões sobre como foram empreendidas as análises dos dados coletados o artigo lançará luz sobre a etapa de construção da teoria, fase de extrema importância para os estudos envolvendo a grounded theory.

\subsection{Construindo a teoria}

A partir das análises conduzidas conforme estabelecido operacionalmente pela grounded theory, foi possível iniciar a proposição da teoria substantiva, a partir da elaboração de uma série de esquemas para apresentar tanto as propriedades de cada categoria emergente da análise quanto as relações entre as categorias. Também nessa fase foi possível perceber alguns pontos de aderência entre a grounded theory e a etnografia. A primeira delas tem a ver com a riqueza de descrição das diversas categorias que emergiram no trabalho de campo proporcionada pelo estudo de cunho etnográfico. Em estudos clássicos da grounded theory essa descrição detalhada fica prejudicada visto que os pesquisadores focam na construção da teoria. Outro ponto está relacionado ao adensamento das categorias que puderam contar com maiores detalhes favorecimento o estabelecimento de propriedades e relações, de fato, fundamentadas no cotidiano dos pesquisados. Por exemplo, a categoria central da teoria foi "questões simbólicas envolvendo a experiência de eletrônicos por consumidores de baixa renda". Para embasar a escolha da categoria central foi essencial a descrição da forma os consumidores transferem em suas experiências de consumo com os aparelhos eletrônicos uma forte carga simbólica, ou seja, por meio de uma série de sentimentos como sensação de conquista e recompensa, forma de satisfação dos filhos, meio de diferenciação entre os moradores e possibilidade de reunir a família. A experiência de consumo, portanto, parece levar à ocorrência de sensações e sentimentos como cuidados com os aparelhos, "ciúme", gosto por elogios. Ademais, é carregada de questões afetivas, como uso do som e/ou da REAd | Porto Alegre - Edição 78 - N² 2 - maio/agosto 2014 - p. 397-424 
Articulando a Etnografia e a Grounded Theory na pesquisa do consumidor televisão para a reunião de família, "os aparelhos são para todos" e aparelhos fazem parte da vida. Dessa forma, como se revelou nos dados, a posse e a experiência de consumo dos aparelhos eletrônicos por parte dos consumidores de baixa renda não está somente associada a questões utilitárias, mas também a diversos aspectos simbólicos. O valor simbólico dos aparelhos se constrói não somente entre todos os membros das famílias, mas também por meio da rede de relacionamentos, que, por ser ampla, inclui parentes, vizinhos e amigos. Porém, emergiu dos dados que as moradoras, ou "mães de família", exercem papel importante nessa "construção" simbólica, na medida em que constituem a ligação nas famílias.

Não é escusado afirmar nesse ponto que qualquer estudo baseado em uma grounded theory em uma vertente construtivista deve ter a intenção de buscar penetrar na vivência dos pesquisados com foco nos detalhes, mas principalmente nas diferenças, nas incoerências e nas ambiguidades do mundo deles a fim de ampliar o entendimento sobre o mundo em que vivem os informantes.

Assim, o Quadro 6 tenta sumarizar essas questões apontando os aspectos importantes da etnografia, da grounded theory e os pontos de aderência entre ambas nessa fase da pesquisa.

Quadro 6 - Pontos de aderência entre a etnografia e a grounded theory na fase de construção da teoria

\begin{tabular}{|l|l|l|}
\hline \multicolumn{1}{|c|}{ ETNOGRAFIA } & \multicolumn{1}{|c|}{ PONTOS DE ADERÊNCIA } & \multicolumn{1}{c|}{ GROUNDED THEORY } \\
\hline $\begin{array}{l}\text { O trabalho de campo com a } \\
\text { elaboração de diários de } \\
\text { campo e anotações sobre a } \\
\text { observação participante }\end{array}$ & $\begin{array}{l}\text { Riqueza das categorias } \\
\text { Adensamento das categorias } \\
\text { Descrição das relações }\end{array}$ & $\begin{array}{l}\text { Definição da categoria } \\
\text { central da teoria } \\
\text { Apontamento das } \\
\text { propriedades e relações entre } \\
\text { as categorias } \\
\text { Construção de esquemas para } \\
\text { construir a teoria }\end{array}$ \\
& &
\end{tabular}

Fonte: Elaborado pelo autor

Após a construção da teoria, outra fase importante é o da retorno ou (re)encontro com a literatura. A próxima seção apresenta comentários sobre essa etapa.

\subsection{Retornando à literatura}

Conforme já enfatizado anteriormente, uma teoria fundamentada nos dados não se limita somente a coletar dados e analisa-los com o intuito de verificar ou refutar teorias preexistentes, construídas em outros contextos e por outros pesquisadores. Seu foco é justamente fazer emergir, de forma criativa e rigorosa, uma teoria a partir dos dados, capaz de 


\section{Marcelo de Rezende Pinto}

explicar um determinado fenômeno em uma área substantiva (TAROZZI, 2011). Para o pesquisador incauto pode ficar a dúvida quanto à utilização da literatura existente sobre as temáticas envolvidas. Cabe destacar que o retorno à literatura constitui-se uma etapa importante em estudos envolvendo a grounded theory, pois o retorno ao conhecimento existente sobre a temática pode ser um estágio importante no sentido de que os resultados possam ser confrontados com a literatura tanto para confirmá-los quanto para apontar onde a literatura é falha, excessivamente simplista ou explica o fenômeno apenas parcialmente (STRAUSS e CORBIN, 2008). Isto é, "trazer a literatura para a redação não apenas demonstra sentido acadêmico, mas também permite ampliar, validar e refinar o conhecimento no campo" (STRAUSS e CORBIN, 2008, p. 61). Ademais, segundo Charmaz (2006), essa etapa é uma oportunidade para os pesquisadores demonstrarem domínio dos trabalhos relevantes já empreendidos no campo de estudo, mostrar sua competência para identificar e discutir as mais significantes ideias e contribuições desses trabalhos, assim como explicitar interlocuções entre a teoria gerada e os estudos anteriores.

Levando-se em consideração a articulação entre a etnografia e a grounded theory, o Quadro 7 sumariza os principais pontos.

Quadro 7 - Pontos de aderência entre a etnografia e a grounded theory no retorno à literatura

\begin{tabular}{|l|l|l|}
\hline \multicolumn{1}{|c|}{ ETNOGRAFIA } & \multicolumn{1}{|c|}{ PONTOS DE ADERÊNCIA } & \multicolumn{1}{c|}{ GROUNDED THEORY } \\
\hline A etnografia produz êxito & A etnografia mostrou-se útil & A literatura deve ser \\
descritivo pois proporciona & na fase de retorno à literatura & consultada após a construção \\
análise detalhada do contexto & visto que as descrições & da teoria a fim de se \\
observado. & detalhadas do fenômeno & identificar onde a literatura é \\
& observado serviram de base & falha, excessivamente \\
& para o adensamento teórico e & simplista ou explica o \\
& a melhor comparação com & fenômeno apenas \\
& outros estudos envolvendo a & parcialmente. \\
& área substantiva. & \\
\hline
\end{tabular}

Fonte: Elaborado pelo autor

Esgotadas as discussões referentes as diversas fases que fizeram parte da pesquisa, julgou-se adequado tecer alguns comentários acerca dos desafios enfrentados pelo pesquisador ao longo dos vários meses que o mesmo se dedicou à investigação.

\section{APONTANDO OS DESAFIOS ENFRENTADOS}

Lançar-se na "aventura" de fazer um trabalho etnográfico e contorná-lo com os pressupostos da grounded theory na pesquisa do consumidor permitiu ao pesquisador REAd | Porto Alegre - Edição 78 - N 2 - maio/agosto 2014 - p. 397-424 
Articulando a Etnografia e a Grounded Theory na pesquisa do consumidor "acessar" diversos sentimentos ao longo de todo o processo da pesquisa. De um lado, tal como apontado por Tarozzi (2011, p. 58), um estudo com base na grounded theory "tem em si a exploração, a maravilha, a curiosidade, o esforço, a aventura, a incerteza, a desorientação, o risco". Por outro lado, exigiu uma considerável dose de "ousadia" e força de vontade, ao mesmo tempo em que o forçou a ser humilde e paciente em cada uma das fases da pesquisa. Ficam evidentes, portanto, que muitos foram os desafios enfrentados ao longo de todo o processo da pesquisa.

A primeira questão tem a ver com a inexperiência do autor na condução de uma etnografia que pode ter levado a equívocos em sua visão interpretativa. Ademais, conviver com a ambigüidade oriunda do dito e não feito, do feito e não dito quando se confronta o discurso e o dia a dia dos entrevistados ainda é incômoda para muitos pesquisadores. Outra consideração relevante é a questão da subjetividade característica da etnografia que impõe ao pesquisador o uso da primeira pessoa nos tempos verbais. Contrapor e enfrentar essa imposição com a necessidade de impessoalidade exigida pela academia foi uma tarefa penosa e até desgastante no relacionamento com os "pares não iniciados", ainda que os novos referenciais ligados ao pós-positivismo e ao construcionismo social adotem essa prática sem maiores questionamentos. Além disso, o extenso tempo necessário para permanecer em campo, questão essencial para um estudo de cunho etnográfico, é outro aspecto desafiador da utilização da etnografia. Atrelado a isso, as constantes idas e vindas a campo em busca de novos dados para adensar as categorias passa a ser algo desgastante que chega a gerar alguma ansiedade no pesquisador que, quase invariavelmente, é apressado pelos prazos de entrega do trabalho em fase final.

O segundo desafio está relacionado à quase inexistência de textos sobre a forma de operacionalização da grounded theory. Boa parte dos pesquisadores simpatizantes deste "movimento" de pesquisa se limita a construir seu histórico, discutir suas características e fazer comparações com outros métodos de pesquisa. Pouco se publicou no exterior e principalmente em língua portuguesa sobre como realmente se pode conduzir uma pesquisa baseada na grounded theory. Menos ainda, não foi encontrado nenhum trabalho nesse sentido, sobre como "costurar" em um mesmo desenho de pesquisa abordagens metodológicas com origens distintas, com autores oriundos de escolas de pensamento diversas.

Relacionado às duas questões discutidas anteriormente, outro desafio marcante durante o processo da pesquisa foi a dificuldade de interlocução com outros pesquisadores conhecedores e usuários de ambas as abordagens. Isso fatalmente levou o pesquisador a um REAd | Porto Alegre - Edição 78 - N² 2 - maio/agosto 2014 - p. 397-424 


\section{Marcelo de Rezende Pinto}

sentimento constante de "estranho no ninho". Ao se aproximar do grupo de etnógrafos, a indicação era de que a etnografia bastava por si mesma, ou seja, a descrição da realidade dos sujeitos pesquisados baseado na observação participante e nas entrevistas em profundidade era suficiente para se entender o fenômeno sob investigação. Ao levar o trabalho para o lado dos adeptos da grounded theory, havia sempre o questionamento do porquê utilizar também a etnografia se os autores da correntes interpretativista da grounded theory já ofereciam um arsenal bastante potente para a coleta e análise dos dados. Por sua vez, ao apresentar a proposta da articulação para alguns pesquisadores do campo do comportamento do consumidor, a indagação quase sempre trazida à tona era: onde está seu modelo teórico? ou ainda, qual escala de mensuração você utilizará?

O retorno à literatura também apresenta alguns desafios principalmente quando a pesquisa está situada em um campo ainda pouco explorado por outros estudos. O pesquisador, nesse caso, se vê com dificuldades em confrontar seus dados e "testar" o poder explicativo de sua teoria substantiva.

Com o término da pesquisa, ainda sobram algumas dúvidas e incertezas e se anuncia um novo desafio que está relacionado com a divulgação dos resultados do trabalho. Em se tratando de uma pesquisa que buscou articular metodologias e "estilos" pouco usuais na pesquisa do consumidor, e sobre as quais poucos pesquisadores conhecem a fundo, algumas perguntas parecem emergir: Será que conseguirei publicar meu trabalho? Quais periódicos estarão "abertos" a publicar meus trabalhos? Os avaliadores entenderão minha proposta? Quão posso ser criticado por tentar fugir dos métodos tradicionais de pesquisa e análise de dados? Posso ser "penalizado" academicamente pelas minhas escolhas metodológicas? Fica fácil perceber que são questionamentos que também remetem a reflexões importantes para os pesquisadores do campo da pesquisa do consumidor no Brasil.

\section{CONSIDERAÇÕES FINAIS}

Ainda que seja possível suscitar alguma polêmica ao se discutir a base epistemológica envolvendo a etnografia e a grounded theory - a primeira tem origem na Antropologia, enquanto boa parte dos autores adeptos da segunda acomodam seus pressupostos básicos no Interacionismo Simbólico - adotou-se uma postura menos ortodoxa e mais aberta à conversação entre diferentes abordagens e métodos de pesquisa (LEWIS e GRIMES, 1999;

REAd | Porto Alegre - Edição 78 - N 2 - maio/agosto 2014 - p. 397-424 
Articulando a Etnografia e a Grounded Theory na pesquisa do consumidor

CRESWELL, 2007), defende-se que é possível tentar conciliar as características da etnografia e da grounded theory.

Nesse sentido, enquanto a etnografia ofereceria condições de estar em campo, de dar oportunidade aos pesquisadores de vivenciar o dia a dia dos consumidores no seu ambiente e construir um conhecimento "comum" a ambos, na grounded theory o pesquisador contempla a possibilidade de ir além das descrições, tão comuns nos estudos etnográficos, com a "construção" de uma teoria focada naquela situação de consumo específica. Dessa forma, é possível direcionar esforços no sentido de vislumbrar o estabelecimento de uma "lógica" de pesquisa que permita a construção de "pequenas" teorias preocupadas em efetivamente dialogar com a "realidade" dos sujeitos pesquisados, tratando os consumidores em relação uns com os outros e com o mundo próprio deles, com o intuito de investigar toda a riqueza de situações proporcionadas pelo cotidiano, pela "vida vivida" no dia a dia. Assim, não é escusado afirmar que ao trazer a baila a "realidade comum" de pessoas que trabalham, se relacionam, sonham, consomem, enfim, vivem em diferentes contextos, pode-se chegar à construção de "ricas" descrições da realidade nacional acompanhadas por teorias locais, alternativas à literatura predominantemente estrangeira, fundamentadas nas peculiaridades culturais e sociais do consumidor brasileiro.

Ademais, parece ser plausível e adequado mesclar a disciplina do estilo grounded theory com os insights da postura etnográfica, uma vez que essa articulação pode ajudar na busca do equilíbrio dinâmico entre aproximação e estranhamento. Isto é, enquanto a adoção de um estilo grounded theory auxilia o pesquisador a lidar com a "riqueza" dos dados "de perto e de dentro" permitindo que ele amplie as fronteiras analíticas e a sofisticação teórica do seu trabalho "de campo", uma postura etnográfica certamente colabora de maneira decisiva para humanizar a grounded theory, para reduzir a distância entre $a$ teoria fundamentada e "a realidade que a fundamenta" aproximando os pesquisadores do contexto e dos informantes da pesquisa de modo que ele possa entender as experiências não só a partir de como as pessoas falam sobre ela, mas também de como elas são realmente vividas. Em se tratando das experiências relacionadas ao consumo em toda a sua complexidade, estas questões parecem fazer sentido.

Levando-se em consideração os pesquisadores que já ousaram inserir na pesquisa do consumidor a utilização de técnicas etnográficas (ARNOULD e WALLENDORF, 1994; SANDERS, 1987; ELLIOT e JANKEL-ELLIOTT, 2003; GOULDING, 2005; MARIAMPOLSKI, 2006; KATES, 2006; SHERRY, 2006; SUNDERLAND e DENNY, REAd | Porto Alegre - Edição 78 - N² 2 - maio/agosto 2014 - p. 397-424 


\section{Marcelo de Rezende Pinto}

2007) e retornando aos autores que propuseram a articulação de forma especulativa entre as duas metodologias discutidas na seção introdutória desse trabalho (PETTIGREW, 2000; GOULDING, 2005; AYROSA e SAUERBRONN, 2006; CHARMAZ e MITCHELL, 2001; LOURENÇO et al, 2007; PINTO e SANTOS, 2008), não seria inadequado enfatizar que o artigo oferece como contribuição para os pesquisadores do consumidor justamente algumas indicações de como fazer "conversar" as duas possibilidades metodológicas em um mesmo desenho de pesquisa contadas por quem, de fato, vivenciou todo o processo. Além disso, o estudo parece estar alinhado com a tendência nos últimos anos de incorporação de novos referenciais e possibilidade de conversação (HOLBROOK, 1987; BELK, 1995; ZALTMAN, 2000; McCRACKEN, 2003; BELK, 2006).

Contudo, a articulação entre a etnografia e a grounded theory não deve ser considerada uma "panacéia" ou uma possibilidade metodológica livre de limitações e imperfeições ao se pesquisar o consumidor. É perfeitamente adequado afirmar que uma pesquisa com este desenho demanda tempo e dedicação por parte do (s) pesquisador (es). Quase sempre, é essencial passar meses em campo até que a teoria possa estar em um estágio considerado "adequado", ou seja, densa o suficiente para, de fato, conseguir explicar uma realidade relacionada a alguma situação de consumo. É necessário ainda que o(s) pesquisador (es) esteja(m) aberto(s) para encontrar resultados "não esperados" e situações imprevistas.

Ademais, tendo em vista a flexibilidade da proposta, muitas outras possibilidades de percurso podem ser vislumbradas em cada uma das fases da pesquisa. Sem o intuito de se tornar exaustivo, métodos diferenciados de coleta de dados poderiam ser considerados no trabalho de campo como técnicas projetivas, story telling, utilização de metáforas, história oral, além da videografia e fotoetnografia entre outras para adensar o corpus. Na etapa de análise de dados, podem ser apontadas inúmeras possibilidades de análise de discurso. Dessa forma, todos esses pontos podem ser entendidos como propostas para futuros trabalhos a serem conduzidos por pesquisadores dispostos a enfrentar os desafios aqui discutidos. Vale enfatizar que somente a proliferação de trabalhos envolvendo tais perspectivas no campo da pesquisa do consumidor é que permitirá criar um "arsenal" amplo e consistente de métodos e técnicas capaz de permitir "arranhar" a complexidade do consumo como fenômeno social e culturalmente construído.

Com essas considerações, não seria adequado dizer que o trabalho terminou aqui, muito menos que o debate deva ser considerado encerrado em apenas um trabalho. Pelo contrário, ou seja, tentar "enquadrar" todas as possibilidades de pesquisa descortinada pela REAd | Porto Alegre - Edição 78 - N² 2 - maio/agosto 2014 - p. 397-424 
Articulando a Etnografia e a Grounded Theory na pesquisa do consumidor proposta de articular a etnografia e a grounded theory em um único artigo é, no mínimo, ter uma visão estreita sobre o tema. Recuperando o que foi dito na introdução, a intenção não foi "fechar" questões, mas, sobretudo, trazer o convite para o debate e para a troca de experiências e interlocuções entre diversos campos do conhecimento.

\section{REFERÊNCIAS}

ALCADIPANI, R. Violência e Masculinidade nas Relações de Trabalho: Imagens do campo em pesquisa etnográfica. Cadernos EBAPE.BR, v. 8. n. 1, p. 93-110, Mar. 2010.

ANDION, C.; SERVA, M. A Etnografia e os Estudos Organizacionais. IN: GODOI, C. K; BANDEIRA-DE-MELLO, R.; SILVA, A. B. (org.) Pesquisa Qualitativa em Estudos Organizacionais: paradigmas, estratégias e métodos. São Paulo: Saraiva, 2006.

ARNOULD, E.; WALLENDORF, M. Marketing-oriented Ethnography: interpretation building and marketing strategy formulation. Journal of Marketing Research. V. 31, p. 484504, nov 1994.

ATKINSON, P.; COFFEY, A.; DELAMONT, S.; LOFLAND, J.; LOFLAND, L. Editorial Introduction. In: ATKINSON, Paul; COFFEY, Amanda; DELAMONT, Sara; LOFLAND, John; LOFLAND, Lyn. Handbook of Ethnography. London: Sage Publications, 2001.

AYROSA, E. A. T.; SAUERBRONN, J. F. R. Uma introdução ao Uso de Métodos Qualitativos de Pesquisa em Comportamento do Consumidor. IN: VIEIRA, M. M. F.; ZOUAN, D. M. (org). Pesquisa Qualitativa em Administração. $2^{a}$ ed. Rio de Janeiro: Fundação Getúlio Vargas, 2006.

BANDEIRA-DE-MELLO, R.; CUNHA, C. J. C. de A. Grounded theory. In: GODOI, C. K.; BANDEIRA-DE-MELLO, R.; SILVA, A. B. Pesquisa qualitativa em estudos organizacionais: paradigmas, estratégias e métodos. São Paulo: Saraiva, 2006.

.; GARREAU, L. The Use of Art Knowledge to Enhance Creativity in Grounded Theory Research. In: EnANPAD, 33º. Anais... São Paulo: ANPAD, 2009.

BARBOSA, L. Marketing Etnográfico: colocando a Etnografia em seu Devido Lugar. Revista de Administração de Empresas (RAE), v.43, n.3, p.100-105, 2003.

BARDIN, L. Análise de Conteúdo. São Paulo: Edições 70, 2011. REAd | Porto Alegre - Edição 78 - N² 2 - maio/agosto 2014 - p. 397-424 
Marcelo de Rezende Pinto

BARROS, C. F. Marketing e Etnografia: um levantamento em journals dos anos 80 e 90. In: EnANPAD, 26 ${ }^{\circ}$. Anais... Salvador-BA: ANPAD, 2002.

BELK, R. W. Studies in the New Consumer Behaviour. IN: MILLER, Daniel.

Acknowledging Consumption. New York: Routledge, 1995.

BELK, R. W. Handbook of Qualitative Research Methods in Marketing. Northampton: Edward Elgar Publishing, 2006.

CARISIO, C. M.; FONSECA, A. M. O.; CHIARI, E. D.; SILVA, S. C.; REIS, M. C.; VALADÃO JÚNIOR, V. M. Pesquisa da Imagem de uma Mineradora e a Grounded Theory: uma possibilidade metodológica para os estudos organizacionais. In: EnEO, $5^{\circ}$. Anais... Belo Horizonte: ANPAD, 2008.

CHARMAZ, K. Constructing grounded theory: a practical guide through qualitative analysis. London: Sage Publications, 2006.

; MITCHELL, R. An Invitation to Grounded Theory in Ethnography. In: ATKINSON, P.; COFFEY, A.; DELAMONT, S.; LOFLAND, J.; LOFLAND, L. Handbook of Ethnography. London: Sage Publications, 2001.

CRESWELL, J. W. Projeto de Pesquisa: métodos qualitativos, quantitativo e misto. $2^{\text {a }}$. ed. Porto Alegre: Artmed, 2007.

DENZIN, N. K.; LINCOLN, Y. S. O Planejamento da Pesquisa Qualitativa: Teorias e Abordagens. $2^{\mathrm{a}}$ edição. Porto Alegre: Bookman, 2006.

DEY, I. Grounding Grounded Theory: guidelines for qualitative inquiry. San Diego, USA: Academic Press, 1999.

ELLIOTT, R.; JANKEL-ELLIOTT, N. Using ethnography is strategic consumer research. Qualitative Market Research, v.6, n.4, 2003.

FETTERMAN, D. M. Ethnography. Thousand-Oaks: Sage, 1998.

FINE, G. A. Towards a peopled ethnography: Developing theory from group life.

Ethnography, v. 4, n. 1, p. 41-60, 2003.

REAd | Porto Alegre - Edição 78 - N² 2 - maio/agosto 2014 - p. 397-424 
Articulando a Etnografia e a Grounded Theory na pesquisa do consumidor

FLORES-PEREIRA, M. T.; CAVEDON, N. R. Os Bastidores de um Estudo Etnográfico: Trilhando os caminhos teóricos-empíricos para desvendar as culturas organizacionais de uma livraria em shopping Center. Cadernos EBAPE.BR, v. 7. n. 1, p. 153-168, Mar. 2009.

GEERTZ, C. A Interpretação das Culturas. Rio de Janeiro: Jorge Zahar Editora, 1978.

GLASER, B. Basics of Grounded Theory Analysis. Mill Valley, CA: Sociology Press, 1992.

; STRAUSS, A. The Discovery of Grounded Theory: Strategies for qualitative research. New York: Aldine, 1967.

GOULDING, C. Grounded Theory: a practical guide for management, business and market researchers. London: Sage Publications, 2002.

Grounded Theory, Ethnography and Phenomenology: a comparative analysis of three qualitative strategies for marketing research. European Journal of Marketing, v. 39, n. 3/4, p. 294-308, 2005.

HAMMERSLEY, M. What's Wrong with Ethnography? London: Routledge, 1992.

HOLBROOK, M. B. What is Consumer Research? Journal of Consumer Research, v. 14, p. 128-132, june 1987.

ICHIKAWA, E. Y.; SANTOS, L. W. Apresentando a Grounded Theory: uma nova proposta de abordagem qualitativa na pesquisa organizacional. In: EnANPAD, 25․ Anais... Campinas: ANPAD, 2001.

KATES, S. M. Researching Brands Ethnographically: an interpretive community approach. In: BELK, R. W. Handbook of Qualitative Research Methods in Marketing. Northampton: Edward Elgar Publishing, 2006.

LAVILLE, C.; DIONNE, J. A Construção do Saber: manual de metodologia da pesquisa em ciências humanas. Porto Alegre: Artes Médicas Sul; Belo Horizonte: EDUFMG, 1999.

LEWIS, M; GRIMES, A. Metatriangulation: building theory from multiple paradigms. Academy of Management Review, v. 24, n. 4, p. 672-690, 1999.

LOCKE, K. Grounded Theory in Management Research. London:Sage Publications, 2001. REAd | Porto Alegre - Edição 78 - N 2 - maio/agosto 2014 - p. 397-424 
Marcelo de Rezende Pinto

LOURENÇO, C. D. S.; FERREIRA, P. A.; ROSA, A. R.; SILVA, S. S. Etnografia e Grounded Theory na Pesquisa de Marketing de Relacionamento no Mercado Consumidor: Uma Proposta Metodológica. In: EnEPQ, 1º. Anais ... Recife: ANPAD, 2007.

MALINOWSKI, B. K. Argonautas do Pacífico Ocidental: um relato do empreendimento e da aventura dos nativos no arquipélago da Nova Guiné. São Paulo: Abril Cultural, 1978.

MARIAMPOLSKI, H. Ethnography for Marketers: a guide to consumer immersion. London: Sage Publications, 2006.

MARÇAL, M. C. C.; BRANDÃO, H. A. O Encontro da Etnografia com as Consumidoras de um Fitness Center: o [des]velar de um caminho metodológico. In: EMA, 3, 2008, CuritibaPR. Anais... Curitiba: 2008.

MCCRACKEN, G. Cultura e Consumo: novas abordagens ao caráter simbólico dos bens e das atividades de consumo. Rio de Janeiro: Mauad, 2003.

MELLO, R. B. Uma Teoria Substantiva da Adaptação Estratégica a Ambientes Turbulentos e com Forte Influência Governamental: o caso das pequenas construtoras de edificações. 242 f. Tese (Doutorado em Engenharia de Produção) - Programa de Pósgraduação em Engenharia de Produção da UFSC, Florianópolis, 2002.

PETRINI, M.; POZZEBON, M. Usando a Grounded Theory na Construção de Modelos Teóricos. In: EnANPAD, 32 . Anais... Rio de Janeiro: ANPAD, 2008.

PETTIGREW, S. F. Etnography and Grounded Theory: a happy marriage ? Advances in Consumer Research. v. 27, p. 256-260, 2000.

PINTO, M. de R.; SANTOS, L. L. S. Em Busca de uma Trilha Interpretativista para a Pesquisa do Consumidor: Uma Proposta Baseada na Fenomenologia, na Etnografia e na Grounded Theory. RAE-Eletrônica, v. 7, n. 2, jul./dez. 2008.

; SANTOS, L. L. S. A Grounded Theory como abordagem metodológica. Organizações \& Sociedade, v. 19, n. 62, p. 417-436, jul.-set. 2012. 
Articulando a Etnografia e a Grounded Theory na pesquisa do consumidor

ROCHA, E.; BLAJBERG, C.; OUCHI, C.; BALLVÉ, F.; SOARES, J.; BELLIA, L.; LEITE, M. Cultura e Consumo: um roteiro de estudos e pesquisas. In: EnANPAD, $23^{\circ}$. Anais... Foz do Iguaçu: ANPAD, 1999.

; BARROS, C. F. P. Dimensões Culturais do Marketing: teoria antropológica, estudos etnográficos e comportamento do consumidor. In: EnANPAD, 28 . Anais... Curitiba: ANPAD, 2004.

SANDERS, C. R. Consuming as Social Action: Ethnographic methods in consumer research. Advances in Consumer Research. V. 14. p. 71-75. 1987.

SHERRY, J. F. Fielding Ethnographic Team: strategy, implementation and evaluation. In: BELK, R. W. Handbook of Qualitative Research Methods in Marketing. Northampton: Edward Elgar Publishing, 2006.

STRAUSS, A.; CORBIN, J. Pesquisa Qualitativa: Técnicas e procedimentos para o desenvolvimento da teoria fundamentada. $2^{a}$ edição. Porto Alegre: Artmed, 2008.

SUNDERLAND, P. L.; DENNY, R. M. Doing Anthropology in Consumer Research. Walnut Creek: Left Coast Press, 2007.

TAROZZI, M. O que é a Grounded Theory? Metodologia de pesquisa e de teoria fundamentada nos dados. Petrópolis-RJ: Vozes, 2011.

ZALTMAN, G. Consumer researchers: take a hike! Journal of Consumer Research, v. 26, p. 423-428, Mar. 2000. 